\title{
Overcoming Vulnerability: Life Stories of Two Cases Women Primary School Principals in the District of Abidjan, Côte D'Ivoire (Ivory Coast)
}

\author{
Rassidy Oyeniran* (corresponding author) \\ Département des Sciences de l'Éducation \\ 08 B.P 2098 Abidjan 08, Côte d'Ivoire \\ E-mail: hariel.or1@gmail.com \\ Amalaman Franck Severin ANDO \\ Département de Psychologie \\ Université Félix Houphouët-Boigny \\ 01 BP Abidjan, Cocody, Côte d'Ivoire \\ E-mail: franck.ando@hotmail.com \\ Isidore Tra Bi Tra \\ Département de Psychologie \\ Université Félix Houphouët-Boigny \\ 01 BP Abidjan, Cocody, Côte d'Ivoire \\ E-mail: tra2isidore@yahoo.fr
}

Institut Pédagogique National de l'Enseignement Technique et Professionnel (IPNETP)

Received: March 11, 2021

Accepted: July 2, $2021 \quad$ Published: August 1, 2021

doi:10.5296/jse.v11i3.18402

URL: https://doi.org/10.5296/jse.v11i3.18402

\begin{abstract}
The present study explores the life story that characterizes each of the selected women and how they get out with challenged conditions to conquer school principal-ship. The study used qualitative data to extract two (2) women principals' meanings through
\end{abstract}




\section{Macrothink}

Journal of Studies in Education

ISSN 2162-6952 2021, Vol. 11, No. 3

in-deep interviews. The selected women principals were presented as case studies because of their potential backgrounds and experience. Ten (10) teachers randomly selected also take part in the study. The research employed a phenomenological case study approach based on the following factors: Perceptions, feelings, experiences, and resiliencies. The findings enlightened women principal's principal-ship experiences, social roles, family and work obligations that they have to deal with in vulnerable situations. The paper also pointed out how these women surpass the barriers they encounter. The article proposes to create the educational, institutional and environmental conditions in order to make use of the potentialities of female, especially women school principals, for the success of the students.

Keywords: Women education, Life story, Principalship, Role conflict 


\section{Introduction}

It is known that women in Africa face barriers to becoming leaders (Steady, 2011). Social and cultural barriers are some these obstacles women have to deal with in school settings. While the World Conference of Women, held in Beijing in 1995 recommended 30\% of women in all public sectors in order to increase their representativeness. In Côte d'Ivoire, women heads play a valuable role in the management of schools and educational institutions. The increasingly noticed presence of women in public services encourages people to pay attention to their contribution to the management of organizations and above all to take a more careful look at organizational culture.

Women's access to decision-making positions is always like the glass ceiling. Following the international conferences (Copenhagen, Nairobi, Cairo and Beijing), the political will of governments was expressed, on the one hand, through the appointment of women and on the other hand through the opening up of positions to women hitherto reserved for men such as the army, the police, and the Civil Service.

Currently, the efforts made by the Ivorian government led to noticeable results in various decision-making positions. Since April 6th, 2021 the number of women in the government rose from 6 to 8 . Obviously, that is still not enough.

In addition, the article 36 of the 2016 Constitution imposes $30 \%$ of female on the selected candidates in the political parties. Actually, this article specifies that the State is committed to promoting the political rights of women by increasing their number in elected assemblies. This is reinforced by other legal instruments such as the electoral code which specifies in its article 71 "no list can be accepted if in a constituency of more than two (2) seats it does not include at least 30\%". Although these mechanisms exist and measures have been taken in favor of women, only more than $13 \%$ of women were interested in the legislative elections of 2021 in Côte d'Ivoire. The quota of $30 \%$ was not reached by any party, not even within the RHDP (the political ruling party) which tried, and encouraged women to get involved. That was particularly pushed by the Secretary-General, Mrs Kandia Camara a woman known for her strong personality.

Moreover, the education sector in Côte d'Ivoire remains male-dominated. Several factors prevent women from seeking leadership positions: Discrimination, doubts, ignorance, or negation of female values and skills.

On other hand, perceptions against women were strong, and the omnipresence of men in the educational field was the rule, but it did not exclude the presence of women. Does this perception of women seem to be linked to the [heavy] cultural heritage of the society? Although things seem to be moving in favor of women, the fact remains that difficulties and barriers are still persistent, preventing women's efforts to run schools. As a result, less opportunity is given to women workers to lead as a school principal, which allow them to express their voices. To understand the depth of the realities experienced by women as school manager, this article described two women experiences who are school principals in Abidjan. Considering the school attainment, gender inequalities, the authors seek to investigate how 
these women influence school management. The present paper intended to create an awareness of the enabling pathways to women's voice and school headship as well as to contribute to the literature on education.

\subsection{Purpose of the Study}

The purpose of this study is to investigate women principal's principal-ship experience including social roles, family and work duties. The aim is to uncover the true individual professional life and demonstrate that despite their vulnerability how these women surpass the barriers they encounter during their pathway.

\subsection{Research Questions}

- What are the women principals' stories?

- How do women principals overcome the difficulties they encounter?

\section{Methodology}

The study adopted a qualitative research design (Denzin \& Lincoln, 2005; Patton, 2002; Yin, 2014).Qualitative research reveals mainly qualitative data such as opinions, perceptions, life experience Yin, 2014). The study drew its material from two women principals who are part of a more extensive survey in Abidjan District involving ten women principals. A sample of these two women principals was randomly selected. They were presented as case studies because of their potential backgrounds and experience in informing the current research. In addition to women, ten (10) teachers were interviewed. The study used a phenomenological-case study approach. The women principals' perceptions, feelings, experiences, and resiliencies were documented using in-depth interviews. A phenomenological approach helped the researchers gain access to women's lived experiences and understand their leadership perceptions as principals from their perspectives. The case study is "an empirical inquiry that investigates a contemporary phenomenon in its real-life context, especially when the boundaries between phenomenon and context are not evident" (Yin, 2014, p. 16). Here a case study approach enabled a deep understanding of women's school heads particularities and unique meanings. The researchers used narrative inquiry to conduct this research, which allows us to gain insights into their experiences first-hand. The study employed a phenomenology approach to emphasize experiences of the women participants (Moustakas, 1994) to get a deep understand of their professional life. Thus, the phenomenological approach allowed reconstructing the women principals' experience while yielding validity to their narrative. The usefulness of the life history approach lies in allowing qualifying subjects to interpret their own experiences, to understand how the dominant culture has shaped them, analysing the relationship between their biographies, historical events, and the constraints imposed on their personal choices by broader power relations (Morris, 1999). As this case study is qualitative research, the observation was, in addition to interviews, the best way of gathering data as the researchers immersed themselves in the data to understand the actual context of schools. The researchers acted as a nonparticipant observer and noted how women principals reacted and interacted with the school community including parents, teachers, students, and officers within the school context (Creswell, 2013). 


\section{Al Macrothink}

Journal of Studies in Education

ISSN 2162-6952

2021, Vol. 11, No. 3

Thus, data were obtained through the use of qualitative in-depth interviews and observations. Documents were collected to verify some information obtained from the semi-structured interviews. Women principals were interviewed three times and observed forty working days within schools. The researchers informed the participants that they were free to withdraw at any time. The participants were also reassured that their privacy was preserved and hence the use of pseudonyms. The women principals in this particular study expressed how they achieved their goals in running their schools.

\section{Findings and discussion}

\subsection{Participants'profile}

Findings that emerged from this study indicated the women's lived experiences had influenced their leadership, which mainly stem from their education and family background. Besides, in most cases, the regions in which they have been brought up influence their personality and identity, and thereby their leadership styles.

This study narrates in deep the stories of these two women leaders by highlighting different aspects of their personal and professional lived experiences of leadership. This also helps to further the arguments as the case study suggests. Additionally, it gives a deep understanding of women principals' lived leadership experiences by showing the connection between the leadership practices and women principals' lived experiences in their context.

Besides, in Côte d'Ivoire, there are different sections in terms of culture, other traditions, and two main religions, Islam that is practiced by most of the people from the north of Côte d'Ivoire and Christianism practiced by most people from the southern. The two cases of women principals, Ahita from the north and Mouna from the south of the country, were discussed in detail in this chapter because they have been brought up and have pursued their education in these two geographical areas of different traditions. Ahitahad 20 years of teaching experience. Ahita grew up in the Muslim and matriarchal Northern Cote d'Ivoire. Ahita shared that people perceive leadership as a man's role in her community group, and it is not appropriate for women to question. Instead, women should obey her husband. In her village, religion, in general, is one of the challenges towards gender issues, and she is from a polygamous family, which is mostly allowed in the Muslim community. In Islam religion, the belief is that women give much respect to men. That might lead women to be more tolerant and less resistant to men.

Unlike, Mouna was from patriarchal culture and grew up in a Christian community in Abidjan in the southern part of Cote d'Ivoire. She is a sincere Christian, and she has been educated according to her religious practices. Mouna is the first-born daughter in her family and has been educated to be given the responsibility to bring up her siblings and manage her family's affairs.

It's important to present Côte d'Ivoire geographical profile including its map and a glimpse of its sociological image and culture. That would offer the better understanding of Ivorian context overall. 


\section{Macrothink}

Journal of Studies in Education

ISSN 2162-6952 2021, Vol. 11, No. 3

\subsection{Côte d'Ivoire profile}

The following map represents the Ivorian geographical position as well as its ethnic groups.

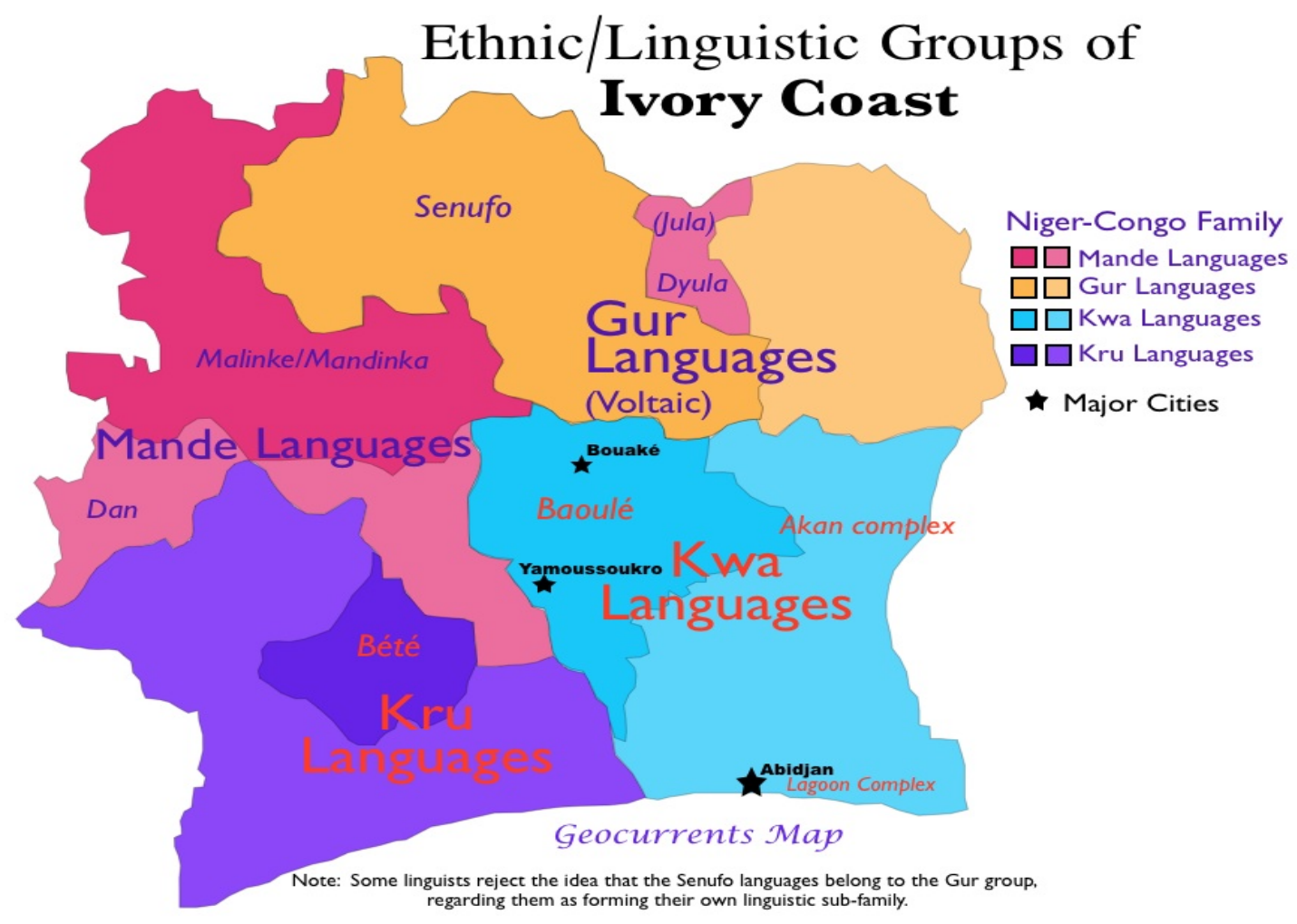

Figure 1. Geographical map of Côte d'Ivoire (Ivory Coast) with ethnic groups

Source: https://www.google.ca/search?q=geographical+map+of

Côte d'Ivoire is a West African country, a member of the African Union. Covering an area of $322,462 \mathrm{~km} 2$, it is bordered to the north by Mali and Burkina Faso, to the west by Liberia and Guinea, to the east by Ghana and to the south by the Atlantic Ocean.

The country's population was around 3 million in 1955. It was estimated at 22,671,331 in 2014; it exceeds 25 million in 2019 and INED projections anticipate a population of over 50 million inhabitants in 2050. Côte d'Ivoire's political and administrative capital is Yamoussoukro (Abidjan remains economic capital), as its official language French and for currency, the CFA franc. The country is part of ECOWAS (Economic Community of West African States: ECOWAS). There are more than sixty (60) peoples including a few main ones: Baoulé, Agni, Malinké, Bété, Gouro, Sénoufo, Lobi, Koulango, Wè.

The population continues to grow rapidly, and is, like everywhere in Africa, congregating around major cities including the metropolis Abidjan, which is now approaching 5 million inhabitants. 


\subsection{Case A: Mouna}

Mouna is a caring person, which is appreciated by her staff. These women's accounts' main areas fall under the following items: Education and family background, and career.

\subsubsection{Her education and Family background}

At the time of the interview, Mouna was 53 years old. She is the second child in a Christian family of eight children, and she attended public school throughout her education. The Christian faith is of great importance in the life of Mouna. She is married and has two children, a girl, and a boy.

Mouna started her teaching job at the age of twenty-five (25). She was in charge of her family including her little brothers, who were still undergraduate students at the National University of Côte d'Ivoire.

Mouna has been generous support to her family over time. She took on the responsibilities with her meagre salary until her young brothers got a job and supported her with family expenses. At home, the atmosphere was quite good. Mouna admitted to having grown up in a harmonious and peaceful family environment with her siblings and other relatives. Although the family education was quite rigorous, she now feels that she has benefited greatly from it. She has been able to help all her brothers and herself be autonomous and be up for the job. Mouna confessed, "the sense of responsibility that my parents taught me still helps me today in my work and my personal life, shaping my readiness for how to live with the people I work with".

\subsubsection{Principal-ship Experiences: Mouna's tendency to leadership}

Mouna has a long experience as a teacher and head of school. Since she entered the principal-ship, she emphasized the importance of teamwork. She always believes that "as head of my school, I don't need to involve myself in a relationship of authority with staff, rather a working relationship and genuine collaboration." Mouna thinks it is the best way to get respect from her teachers, and that luckily increases her influence over them, and they highly esteem her work.

Besides, Mouna felt that sharing responsibility makes teachers feel valued, and this brings a good result of tasks. She perceived headship as a task of organizing people and collaborating with them and caring for them to ensure the school's goals. Mouna believes that empowering others is "my favourite manner of leading as I took it from my education." Mouna's parents played a significant role in her education; she learned from them how to handle and organize people around tasks and engage in doing and coordinating things with family members. Thus, Mouna believes that working in a team, understanding teachers and their job helped her to build relationships that are crucial to her success as a principal-ship. From her point of view, "building positive relationships and personal links with stimulating and supportive roles of empowering teachers" brought an essential level of accomplishment to the workplace.

Being the second child of her family, Mouna found her education quite rigorous. The sense of responsibility gained since parental education helped her as a youth and still helps her today 
in her position, especially how to live and interact with people in an environment where human and cultural diversity invite to work in a context other than the one, she was familiar with. Mouna shared:

... I have been involved in the role and responsibility of helping to know more about how people behave and better understand their situation and concerns. I do not use the old method, which is a dictatorial manner from an old school. We are in a world where we have to let everyone express himself or herself. By doing so, one can play one's role as a school principal without any problem. Being a head of school makes you learn skills on how to manage men. We must let everyone play his or her role. I remember being a teacher. I had a school principal who misbehaved towards myself like a dictator while pregnant nine months pregnant. Once he came to my class, and he saw me sitting. He shouted at me, screaming. He forbade me to sit down when teaching. Yet, I was pregnant, and I found he was unfair towards me. As a principal, I cannot treat others as he did to me. As heads of school, we have to be fair and show at least a little consideration for our school members and understand their situation and help them as much as we can. Today as a principal, I make myself useful as people come to me to tell their stories, and I used to advise as a guidance counsellor. I feel comfortable and valued in this position.

Mouna used to replace teachers and handle their classes when they are absent or delay. She takes a few times to teach and look after the students until he gets back to school. "I do my best to make sure there is no interruption in the school schedule and learning process," she said. The above description shows that women principals had a vision of taking care of their schools and their members, as Muzvidziwa (2014) revealed in her study. Fuller (2014) looks at this characteristic as a feminine quality that kids expect from a woman. Moreover, in her research, Muzvidziwa (2014) reported that the school heads influenced others, motivated, empathized, and were sensitive to community situations.

\subsubsection{Her challenges}

Mouna revealed that "the attitude of some parents is surprising" as she is concerned about improving students' outcomes. She denounced, parents are not involved enough in their kids' learning. She felt the parents are not supportive enough of their kids and the school. She felt disappointed that students fail just because of their parents' attitudes or situations at home. Another challenge that Mouna underlined in the conversation with the researchers is juggling work and domestic affairs. Balancing work and family obligations were also at the center of the discussion with Mouna. Generally, combining the two responsibilities remain a significant concern for women principals in this study. Juggling professional roles and family matters is one of the most significant challenges Mouna has to deal with. She is confronted with how to organize and manage herself to meet the responsibilities of a mother and wife at once while responding to work and satisfying the chief's prerogatives. She said:

In our societies, men do not mind whether their spouses get a job or not (...). They are ready to feed all the family members. So when you work, you are expected to fulfil your domestic duties. 


\section{MIMacrothink}

Journal of Studies in Education

ISSN 2162-6952

2021, Vol. 11, No. 3

Mouna acknowledges that in Côte d'Ivoire, many societies are predominantly patriarchal, and the culture and tradition govern most people's behaviors and actions. Men expect their wives to take care of the children, the household, and daily meals at home. Mouna confessed, "my husband likes to see his dish ready when he gets off work in the evening". This expresses "our culture of privileging the homemade dish rather than eating out". She perceives that "my spouse, being the chief, likes to see our children and myself around him sharing the family meal." When Mouna and her spouse have some visits from parents and friends, her partner prefers to share homemade dishes with them. This is also a way of expressing his control over his family. That makes him comfortable as a father. Mouna views this as, "my husband feels valued among his relatives".

Mouna has to satisfy her home needs and meet the many demands at work. As reported by a teacher (Px3), "Administrative responsibilities do our principal work over time, even on the weekends, and this sometimes affects her health"

Of all the bottlenecks, private and professional life's reconciliation remains a persistent and challenging equation to solve, even though gets support from her husband.

However, Mouna believes that "Very often this affects women in the sense that it reduces opportunities for them to progress in their professional career." Lack of time and availability may discourage women to apply for a higher position. Similarly, if a woman wants to pass a test to get a new or an upper job, she needs to devoted time to studying and preparing for the test; this would require more time while she is already confronted with many occupations. Mouna loves her work but she felt tiring to meet all the enormous administration and home duties' demands. She shared her house constraints:

It is challenging to juggle the two responsibilities. You have to know how to manage these social aspects. For example: "tomorrow Saturday I won't attend the outing that the school is organizing because my husband asks me to do something else for him at home; so I just told the organizing committee of the event that I won't go. It is true, I am the principal, but I am first and foremost a married woman. I acknowledge that my social life is affected, but what can I do... I have to make a choice...the wise choice is to preserve my family interests and my marriage (Field-notes).

The above assertion is consistent with what Oyeniran and Zhang (2020, p.128) posit "that balancing work and home duties were certainly the prime and major concern of women principals in their position." Oyeniran and Zhang (2020) further argued that caring for children at home and fulfilling their duties as wives remain a challenge for women in leadership positions. All these requirements are seen as the most common barrier that women in general face in headship.

\subsubsection{Her gendered experiences}

Mouna has experienced gender stereotypes as a woman and as a leader. Mostly, harmful and undesirable attitudes towards women principals come generally from institutional and structural factors that affect their principalship. Mouna shared a short anecdote: 


\section{Ml Macrothink}

Journal of Studies in Education

ISSN 2162-6952

2021, Vol. 11, No. 3

Two years back, when I was dispatching the class grade to all the teachers, I assign CM2 to a teacher who was absent. The rest of the stages have been chosen by the other teachers. The following day, when he came to school, he contested my decision of assigning to him that class, as he desired to hold grade 4. But I did not give in to his claim because it would not fair if I redistributed the classes, and some of the other teachers might be frustrated. He expected to influence my decision because I am a woman. Finally, he accepted the class after the intervention of two teachers who tried to make him understand and reconsider his position (Note 1)

Mouna believes that these confrontation and insubordination cases come from undermining the women's authority. She has experienced much discrimination against women. She thinks the reason is not only men of her community but also more than "our culture, our social system, and structure."

Mouna acknowledges that leadership skills in Ivorian societies are perceived as stereotypically reserved areas for men since women are perceived as pleasant, friendly, helpful and kind, thereby treating them as "weaker," unable to provide good leadership. It is still difficult for some people to get rid of these stereotypes".

She felt that despite her accomplishment and progress there are still many challenges ahead that remain to be addressed. Exploring the socio-cultural and institutional barriers in the Ivorian context, Oyeniran (2018) found that the school community's negative attitudes towards women principals are embodied in stereotypes and structure of the organization and male-dominated culture.

\subsubsection{Strategies to deal with obstacles}

When asked how Mouna surpasses barriers, she responded, "all depends on the situation, for example, when I deal with a matter concerning teachers' behaviors, most of the time I used patience." Mouna acknowledged that it is not easy to cope with issues "when you are a woman in an administrative position." However, she believes that most of the time, her approach to leading enables her to succeed in controlling things. She shared:

When I faced difficulties that concerned my job, I discuss with my subordinates, which mostly provided, and that opens a deep understanding of the concerns, in this case. I used to associate with the teachers because I feel that I get their agreement and involvement in the tasks through listening, communication, and discussion. Mostly, good ideas and contribution emerge from critical thoughts and debates.

Mouna also used to call and involve parents asking for their opinions on specific issues related to the school activities and affairs before taking an important decision. Mouna believes that "most people do not even realize that leadership is basically about service, about who you are". She said:

It is never about elevating ourselves above others nor about ego. Leadership is about being cooperative and humble so that the people you work with can thrive in ways that create valuable things and empowerment. These have been my most significant observations since I 
lead schools.

Mouna feels that involving parents in the school concerns luckily reinforce the school and community relationships. That is why she loves to get close to the community members.

\subsection{Case B: Ahita}

Her teachers perceive Ahita as a hard worker and innovative person. Like in Mouna's case, Ahita's profile and experiences are explored in this subsection. Ahita's education and family background, career is the main aspects discussed in the following lines.

\subsubsection{Her education and Family background}

Ahita was born and grew up in Katiola, a town located in Northern Cote d'Ivoire. She was teaching in rural areas before being assigned to Abidjan city. At the time of the data collection, Ahita was 45 years old, married with two girls and a boy. Ahita did her elementary school in a rural area in her village and joined her secondary school hometown. She has had a regular school career and finished her schooling with her Baccalaureate after a brilliant pathway. She is still pursuing her study. She applied and succeeded in the educator profession and was waiting on her new ENS (École normale supérieure) training. Her father was a teacher. After ten years of teaching, he became an elementary school principal, then entered the school counseling profession four years later. He is now retired after a long professional experience. Although Ahita's father was an intellectual person, he is driven by ancient cultural traditions and acts accordingly in his life. His grandmother has raised him in his village, a remote area in Katiola. According to the Senoufo (Ethnic group from Northern Côte d'Ivoire) norms, he educated all his children, emphasizing customs. The way he behaves and thinks is mainly embodied in the particular characteristics of his grandfather's lineage. To him, a woman should get married when she was very young. Himself, he married Ahita's mother when she was 17. Ahita did not understand her father's attitude, although she was doing well at school.Ahita said:

I have never failed in my schooling, and my teacher and peers saw me as a bright student. After getting my Baccalaureate degree, I was sent directly, without any test, to CAFOP. Its mission is to train the teachers for primary schools.My older sister was already studying there, while I was eager to join the University.

Ahita was raised in a Muslim family, whileher grandparents remained attached to their traditional beliefs. She grew up in a relatively good family environment. However, Ahita has been under family pressure from her paternal grandmother. Ahita also talked about her tribe where she comes from. Indeed, Ahita belongs to the Tagbana community, a tribe of the large Senoufo ethnic group residing in the northern region of Côte d'Ivoire. In that tribe, the matrilineal system governs society. Thus, matriarchy prevails and dominates in Tagbana's society. Matriarchy is a social system adopted and applied in a matrilineal society, which is a social system in which woman plays a significant role in leading the family and has control of the family property at the specific exclusion of men.

That means children live with the mother's family side, tribe, or clan, no matter how many times the woman gets married. Even though she lives alone or has divorced, her children will 
always remain with her and the family property, so her kids will automatically inherit the family business and rights by succession as a legitimate heir. In Ahita's social group, filiation passes through the mother, who transmits her name and her future inheritance in particular to her children. Hence, Ahita "does not belong" to her father instead of to her mother. That is why her paternal grandmother rejected the idea of schooling Ahita and her other sisters, as she considered that her father was wasting money by paying their school fees every year. Ahita's grandmother was so pushing pressure on her father that he was somehow convinced and was about to deny their education. Ahita related, "Our father even wanted us, daughters, to stop schooling when we reached 20 after". She recalls that her father went through several strategies and attempts to achieve that goal. Fortunately, Ahita's mother has been generous support to her, and she expressed her infinite gratitude to her mother, who believed that education was more important than other matters and useful for her future.

\subsubsection{Principalship Experiences}

Leadership style, challenges, gendered experiences, and strategies to deal with the barriers are the main focus of this subsection.

Ahita's tendency to leadership

Ahita has been running this school for precisely five years, and she perceives herself as a manager who emphasizes instructional practices, hard-working and empowers others. Ahita plays her administrative role by taking into account people's concerns. Her style stemmed from her difficult girlhood and her experiences of life. She firmly believes that "I consider everyone's condition before acting or taking any decision." Ahita, views her leadership as, "I take into consideration the context and the moment; for example, if a teacher is late, I can be flexible on the rules if he has delayed for a good reason." She also tries to understand a painful situation of her teachers and supports them when needed. However, when it comes to working, she becomes challenging, as indicated by a teacher (Px6). That teacher perceives the leadership style of his school head as democratic. According to him, Ahita encourages free self-expression in the school but she is quite strict on the other side and likes details. She used to control everything including the teaching program and its progress.

Ahita perceives a good leader as someone who creates a team and responds to what each member needs, even if they do not always ask directly. She felt that "leadership is mostly about listening. She has discovered that the best teamwork is the one with the best speakers, in terms of setting a vision and responding to individual personalities in your team in effective ways. Doing so, "I can easily take them out and empower them to thrive in their job." For Ahita, her staff need to be involved in accomplishing a good job:

I emphasize communication in my way of working. The teachers and I help each other, and our collaboration go with respect for each other and everyone's role. When asked for a joint project, my team members are very active, supportive, and collaborative. On the other hand, they are difficult to move if you don't share roles. I do not jostle them. Otherwise, they do not follow, and they do not feel concerned. They are very conservative; when we have projects, I have to encourage them to reflect differently and raise questions. This lets ideas flowing as 
brainstorming.

When questioned after the conversation about her commitment to people motivation and inspiration, Ahita simply stated:

Leadership is about inspiring others to raise the positive and best ideas that have never been brought out before; mostly, I do not need to tell my teachers what to do. I try to have each of them know the direction they want to engage in improves efficiency and is also an easy way to ensure they are learning to motivate themselves. I try to demonstrate the actions, attitudes, and values I expect to see in them. I am aware that this requires commitment and discipline from myself. But, I have to be the woman who wants her team to be. Fortunately, I am lucky, as they now feel connected to my vision and ideal, appreciated by me, and inspired to do the same (Field Notes).

From the above, it seemed that Ahita believes that her staff's motivation and harmonious relationships contribute to strengthening her leadership style as when the team members are associated with the management of the school and decision, there is little risk that someone would contest a decision. This shows how that woman was trying to be transformative as she can. Yet she will not be able to reach her full potential and contribute to transformational change in her school and context without developing skills and capacities across various domains.

\subsubsection{Her challenges}

Work responsibilities versus family duties: A difficult balance

When Ahita was nominated as head of school, she realized she was already three months pregnant. While Ahita was pregnant, her husband catered to her. He was quite attentive to her. But, when Ahita gave birth to her boy, she had to resume working a week later even though she felt "it was not easy." She stated, "I was under constant stress because of a load of work to get through on time." Ahita found that being a principal means you ready for a lot of work to do. Ahita complained about the work and family role conflict. She points out that her personal and social life, daily planning, and even her marriage's stability were affected by the administrative occupation. Ahita shared her experience:

The first time when I gave birth to my daughter, I did not receive any maternity allowance, nor did I not take advantage of my maternity leave, as I had a load of work waiting on me. I had to get back to work. It was so hard. I had so much to do in the office while taking care of my baby and doing housework. I was not prepared for juggling administrative duties and family life. I always felt tired and did not have time to rest. When I return to work, I employed a housemaid for cooking and keeping a house clean and tidy. Yet, last year I realized that my repetitive delays for getting home have nearly hit my young couple. I had abandoned all the home tasks in the house helper's hand because I was too busy with administrative affairs; even on the weekends, I had to get in the office. Then my husband complained, as I did not have time to devote to him and my children. After that, tensions arose at home between my spouse and me; he started blaming me for not fulfilling my home duties, and I was under too much pressure..... Then I realized my husband started dating another woman. He changed his habits towards me; 
he became rough and started to get home very late. I have been off sick for a long time. When I recovered, I reorganized and decided to get things back on track. I restarted doing all the housework, I got more involved in the home tasks, and resumed to take care of my husband and my children".

From that experience, Ahita would suggest the Ministry detach principalship from teaching load as women are still holding triple roles: Being in charge of domestic affairs, leading the school, and teaching. Hoping things will change, she suggested, "If we focus on principalship only it will make us more effective".

\subsubsection{Her gendered experiences}

Ahita revealed that contrary to popular opinion, gender-related difficulties do not come only from men. She had more problems with women than with men. She said, "I encountered difficulties with other women who were not helpful at all." After one year in her principalship, she wanted to introduce innovations in the teaching practices and creational activities, so she had to implement new measures. A woman teacher has confronted her with a decision, yet she was one of her best friends since secondary school. Ahita explained that:

She was spreading false rumors about me. She even urged the other teachers to sign a petition against me to get me sacked from the principalship. Can you image? (...) I was distraught that she challenged me, but I controlled myself, keeping my emotion because I was somehow psychologically prepared. I realized that she was aiming for my position. Later on, I heard she was promoted with the help of someone. Although she got promoted, she still attacking me, gossiping about me, and pushing my staff to rise against me".

Ahita felt that women would be hard to manage. She attributes those attitudes of the teacher to the fact that women compare themselves to their women principal; as mothers, they have a family and almost the same home responsibilities as their head; and they are also led by their husbands who used to make decisions at home. Thus, they tend to deny the power of their principal. They hardly accept being under the authority of a woman in their workplace, whoever she is. It may also be a matter of jealousy, envy, and disobedience, according to Ahita.

Actually, in the communities, stereotypes impede the promotion of women into leadership positions. Ahita related that last year a policeman, came earlier in the morning to undermine her authority by humiliating her in front of teachers, other parents, and pupils in her school. The parent was unhappy with what a teacher did to his child because of inappropriate behavior. Ahita explained,

He insulted me and declared that he could not admit that a woman can run a school (...), and I just said it's a matter of charisma. When you have charm, whether you're a man or a woman, you can lead any organization or group of people.

Another issue raised by Ahita what she identified in men's behaviors, a form of male alliance in institutional partnerships, in the face of a preference displayed for a man head, ignoring skills and level of training. Ahita perceives it as discriminatory practices. She stated, "These men's alliances have even provoked violent situations towards me." She felt she was forced to do ten 
times more so that today, she gets recognition. She found that it's always relevant that you have to do more and longer for a credit identical to that of men when you're a woman. Ahita further commented:

Men think that women are weak in making decisions effectively and they lack good leadership skills. In a meeting, men disputed that I took initiatives without consulting them and they feel like I wanted to command them. I even heard unpleasant words on me and I felt perplexed and upset. I was wondering where these attitudes come from. I just used to defend myself by saying that as a human, I also have the right to speak.

Ahita felt that society needs to encourage women so they have that drive to be innovators, have bigger dreams, goals, making the woman realize that she too is equal to a man. Thedescriptive discrimination related to Ahita's situation is consistent with the findings of Elmuti, Jia, and Davis's (2009, p. 80) study, which revealed that "Most males indicated that they feel women do not have equal opportunities in professional development and upward mobility in organizations." We, therefore, argue that there is a need to stop gender bias and understand that both men and women are equal with their limitations and give them equal opportunities so they display their assets, which would benefit our societies overall.

\subsubsection{Strategies to deal with hurdles}

Throughout her personal and career life, Ahita learned a lot and overcame obstacles courageously at each stage by relying on her assets and determination. Ahita used to work overtime and persevere when they encountered difficulties; she tried to create a positive climate over time within schools and attempted to involve parents in their children's school life. She is also very efficient in managing school affairs, as attested by a male teacher (Px2), "She has that sense of communication skills to deal with challenges".

Ahita used to encourage personal development, and she always used an inclusive way of working and making a decision after a collaborative consultation with school staff. She also involved parents in the school concerns to strengthen the relationship between the school and the community. When questioned Ahita about the best way to handle complex situations, she believes that there is no static approach. She explained her view,

Leading people is not easy... it is not a joke. My training in personal development and human resources help me on that side (....) I have some knowledge of how to interact with different personalities of people. I have found that being a leader manages people and infrastructures and deals with personalities, psychologies, and feelings....As you know, human beings are very complex and difficult to catch once for all. You have to adapt your actions to their reactions (Field Notes).

Ahita shared one of her experiences denouncing the disrespectful attitude she would have often suffered from certain people, especially the men who were taken to react to save her vulnerability. She believes that leadership is first and foremost about having a clear vision of things to be done and achieved. Whoever carries this vision, they should not experience negative behavior but rather should be supported and encouraged for the success of the group's common mission. I have convictions for which I work with my colleagues and I share my 
knowledge to help them improve their teaching practice ... and I am fighting to succeed in my mission.

I am thrilled with my career, not because I am the head of school. Initially, this principalship position was not my goal but somewhat satisfied with the way. Despite everything, I succeeded, and I am proud of it because it was not always easy. A path is strewn with obstacles, with painful moments, and I almost stopped several times. Then, my mom caught me and encouraged me. She told me once: Do not fool yourself. It will always be difficult; you will still have to do more. She was referring to being a woman of matriarchal societies. Now I am moving forward thanks to God (Interview).

The above experience highlights the courage that Ahita has demonstrated in her career to continue and persevere. It also shows how her mother was a generous moral and psychological support in her career path to becoming what she is today. We believe that the ability to address challenges and overcome barriers will depend on women being equipped with the skills and capacities of character that will allow women principals to achieve significant change in the service/work of their schools.

\subsection{Common Characteristics of Women Principals' Leadership}

This study shows that there are some common characteristics from two cases. Indeed, women in this study have been brought up in families' environments/backgrounds that influence their perception of leadership and their inclination of direction. Women's childhood experiences have greatly influenced their way of handling complicated situations. These educational leaders rather employed authority, power, and influence to empower their people (caring, motivating, encouraging, advising, solving problems, applying social justice and equity, values that they are intimately attached to). They operated in a shared perspective that involved teachers in the decision-making process, making them comfortable and creating a smooth atmosphere. Also, the women principals' lived experiences as leaders suggest that leadership is a challenging process that involved recuse. For example, Mouna learned that most of the schoolchildren in her school are from less fortunate families and low backgrounds, and these kids need help and attention. Similarly, Ahita realized that school leadership requires shared actions where teachers need monitoring interventions in their job.

We assume that despite their common experiences women principals, in this study, had/demonstrated some uniqueness including background, leadership style, and strong career and helped transform her school members' thoughts and perspectives. Each principal shared a keen passion for creating a change in her school community, and tried to be efficient at work (Principalship) The figure below shows a glimpse of the women principals' experiences in the school context. 


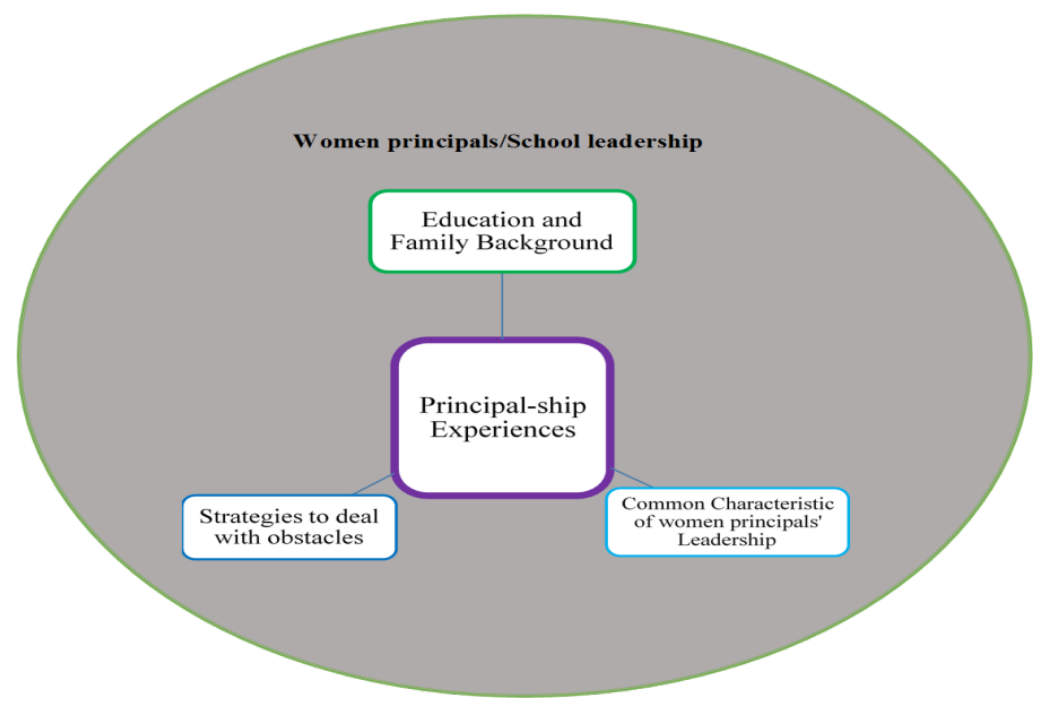

Figure 2. Women principals' experiences in school context

Source: Fieldwork data

\section{Conclusion}

In this paper, two women principals, Mouna and Ahita, were presented as two cases to understand further the lived leadership experiences of women primary school principals in the Côte d'Ivoire context. The paper enlightened their principal-ship experiences, social roles, gender experience, family, and work obligations role conflict. Besides, the discussion critically pointed out how these women surpass their barriers they encounter. Through more in-depth exploration, the findings shed light on how these women operate, emphasizing individualized consideration, collaboration, sharing, and intellectual stimulation. Hence, efforts should be made to reduce many barriers to women's advancement and their day-to-day operations. The present study is also a call for greater attention to women, especially their humanistic quality and ability to manage schools with a purely ethical sense effectively. This is the place to raise awareness of the value of women in Ivorian spaces and accept that women are as much as men capable of leading and accomplishing missions effectively entrusted to them.

\section{Notes}

Note 1. CM2 is grade 6 of primary school in Côte d'Ivoire.

Note 2. CAFOP (Centre d'Animation et de Formation Pédagogique: Center for Animation and Educational Training). CAFOP is the Vocational Training Higher School (Higher School of Vocational Training). ENS (École normale Supérieure) is a Normal school, the higher education institution located in Abidjan, Côte d'Ivoire, created in 1964. Regular school trains high school teachers, inspectors, and educators for two years before.

\section{References}

Creswell, J. W. (2013). Qualitative inquiry and research design: Choosing among five 
approaches. (3rd ed.). Thousand Oaks: Sage.

Denzin, N. K., \& Lincoln, Y. (2005). (eds). The Landscape of qualitative Research Theories and Issues (2nd Ed.). London: Sage.

Elmuti, D., Jia, H., \& Davis, H. H. (2009). Challenges Women Face in Leadership Positions and Organizational Effectiveness: An Investigation. Journal of Leadership Education, 8(2), 167-187. https://doi.org/10.12806/V8/I2/RF4

Fuller, K. (2014) Gendered educational leadership: beneath the monoglossic façade, Gender and Education, 26(4), 321-337. https://doi.org/10.1080/09540253.2014.907393

Kanter, R. M. (1977). Men and Women of the corporation. New-York, Basic Books.

Morris, J. (1999). Managing Women: secondary school principals in Trinidad and Tobago. Gender and Education, 11(3), 343-355. https://doi.org/10.1080/09540259920627

Moustakas, C. (1994). Phenomenological research methods. Thousand Oaks, CA: Sage. https://doi.org/10.4135/9781412995658

Muzvidziwa, I. (2014). Principalship as an Empowering Leadership Process: The Experiences of Women School Heads in Zimbabwe. Anthropologist, 17(1), 213-221. https://doi.org/10.1080/09720073.2014.11891431

Novy-Marx, M. (n,d). Women's transformative leadership in Africa. The MasterCard Foundation Report. Retrieved 2020, December 30th from https://www.issuelab.org/resources/22201/22201.pdf

Patton, M.Q. (2002). Qualitative Research and Evaluation Methods (3rd ed.). Newbury Park, CA: Sage Publication.

Punch, K.F. (2004). Introduction to Social Research, Quantitative and Qualitative Approaches. London: Sage.

Oyeniran, R., (2018). Women Educational Leaders in Principalship: Exploring the Lived Experiences of Women Heading Primary Schools in Côte d'Ivoire. International Journal of Contemporary Education 1(1), 36-51. https://doi.org/10.11114/ijce.v1i1.3209

Oyeniran,R., \& Zhang L. (2020). How do females deal with hindrances in School Headship? Evidences from the Ivorian Context. European Journal of Educational Sciences, 7(2), 116-135. https://doi.org/10.19044/ejes.v7no2a8

Steady F.C. (2011). The Legacy and Importance of Female Leadership in Africa. In: Women and Leadership in West Africa. Palgrave Macmillan, New York. https://doi.org/10.1057/9781137010391_2

Wallace, J., \& Wallin, D. (2015). The voice inside herself': transforming gendered academic identities in educational administration. Gender and Education, 27(4), 412-429. http://dx.doi.org/10.1080/09540253.2015.1019838

Yin, R. K. (2014). Case study research: Design and methods. (5th ed.). SAGE Publications, Inc. https://doi.org/10.1080/09540253.2015.1019838 